Article

\title{
Plasmonic-Layered InAs/InGaAs Quantum-Dots-in-a-Well Pixel Detector for Spectral-Shaping and Photocurrent Enhancement
}

\author{
Jehwan Hwang ${ }^{1,2, \dagger}$, Zahyun Ku ${ }^{3,+}$, Jiyeon Jeon ${ }^{1,4}$, Yeongho Kim ${ }^{1}$, Jun Oh Kim ${ }^{5}$, \\ Deok-Kee Kim ${ }^{4}$, Augustine Urbas ${ }^{3}$, Eun Kyu Kim ${ }^{2, *}$ (i) and Sang Jun Lee ${ }^{1, *}$ \\ 1 Interdisciplinary Materials Measurement Institute, Korea Research Institute of Standards and Science, \\ Daejeon 34113, Korea; wowhwang87@gmail.com (J.H.); jeony210@gmail.com (J.J.); \\ ykim172@kriss.re.kr (Y.K.) \\ 2 Department of Physics and Research Institute for Convergence of Basic Sciences, Hanyang University, \\ Seoul 04763, Korea \\ 3 Materials and Manufacturing Directorate, Air Force Research Laboratory, WPAFB, OH 45433, USA; \\ zahyun.ku.1.ctr@us.af.mil (Z.K.); augustine.urbas@us.af.mil (A.U.) \\ 4 Department of Electronic Engineering, Sejong University, Seoul 05006, Korea; deokkeekim@sejong.ac.kr \\ 5 Advanced Instrumentation Institute, Korea Research Institute of Standards and Science, \\ Daejeon 34113, Korea; jokim@kriss.re.kr \\ * Correspondence: ek-kim@hanyang.ac.kr (E.K.K.); sjlee@kriss.re.kr (S.J.L.) \\ + These authors contributed equally to this work.
}

Received: 11 August 2020; Accepted: 10 September 2020; Published: 13 September 2020

\begin{abstract}
The algorithmic spectrometry as an alternative to traditional approaches has the potential to become the next generation of infrared (IR) spectral sensing technology, which is free of physical optical filters, and only a very small number of data are required from the IR detector. A key requirement is that the detector spectral responses must be engineered to create an optimal basis that efficiently synthesizes spectral information. Light manipulation through metal perforated with a two-dimensional square array of subwavelength holes provides remarkable opportunities to harness the detector response in a way that is incorporated into the detector. Instead of previous experimental efforts mainly focusing on the change over the resonance wavelength by tuning the geometrical parameters of the plasmonic layer, we experimentally and numerically demonstrate the capability for the control over the shape of bias-tunable response spectra using a fixed plasmonic structure as well as the detector sensitivity improvement, which is enabled by the anisotropic dielectric constants of the quantum dots-in-a-well (DWELL) absorber and the presence of electric field along the growth direction. Our work will pave the way for the development of an intelligent IR detector, which is capable of direct viewing of spectral information without utilizing any intervening the spectral filters.
\end{abstract}

Keywords: spectral imaging; plasmonic resonance; metal hole array; quantum dots-in-a-well; electromagnetic simulation

\section{Introduction}

Spectral imaging, also called imaging spectrometry [1,2], is a technology that acquires image information of space and each spectral information at a given scene at the same time and implements it into a spectroscopic imaging data cube. Differently from infrared (IR) imaging acquiring data over the entire wavelength response range of the IR imager, IR spectral imaging uses a spectroscopic system to obtain a series of consecutive spectra for each image pixel. A spatially and spectral-resolved image of the object is analyzed to identify the materials compositions of the object in a scene, and to 
classify materials that are undistinguishable with conventional methods [3-5]. Traditional IR spectral imaging acquires spectral information by placing an optical system such as dispersive or filter-based spectrometers in front of an IR detector [6-8], however there are obstacles to be overcome such as cost, complexity, calibration, and real-time detection. The algorithmic spectrometry [9-16] as an alternative to traditional approaches has been recently developed, and its concept is to reconstruct the spectrum of an unidentified object at a wavelength of interest without utilizing any intervening spectral filters, which is enabled by finding the optimal set of weights by the projection algorithm [17-19]. A set of weights is used to synthesize the arbitrary bandpass filter, which optimally approximates a desired spectral filter shape with a specified center wavelength and bandwidth [20,21]. More importantly, an essential prerequisite to fully benefit from the algorithmic spectrometer for the object detection largely relies on the ability to easily modify the IR detector's responsivity, e.g., peak wavelength, bandwidth, and spectral shape. For this purpose, the physical phenomenon of plasmonic resonance in a metal film perforated with a two-dimensional subwavelength hole array has been the focus of significant interest recently [22-24], because the plasmonic resonance wavelength is simply related to the structural periodicity as well as the detector sensitivity can be improved by integrating the plasmonic resonance layer onto IR detector, resulting from enhancing the coupling to the active region through local field engineering at the plasmonic resonance wavelengths. It is worth pointing out that this perforated metal film structure unconditionally needs to play with the quantum dots (QDs)-based IR detectors [25-37] for spectral-shaping and photocurrent enhancement, which is caused by the anisotropic dielectric constants of the active layer, specifically, the different absorption efficiencies of active layer into $x$ - or $y$-direction (lying in the plane of perforated metal film) and $z$-direction (along the growth direction) [38-45]. It is also worth referring to research on a hybrid device consisting of artificial structure and thermal detector (that can operate at or even above room temperature without cryogenic cooling), which has seen impressive growth, exhibiting the spectral selectivity at the desired wavelength [46-58]. Over the past years, there have been experimental efforts to demonstrate the change of peak wavelength photoresponse at a fixed bias by structural tuning of plasmonic structure (e.g., periodicity or aperture size) [38,43-45]. In contrast, we focus in this letter on control over the shape of bias-dependent wavelength-tunable response spectra using a fixed plasmonic structure (demonstrating the possibility to modify the IR detector's response spectra as desired and to increase the number of different IR detector's responsivities in order to efficiently improve the outcome from the projection step), and at the same time, show the detector responsivity enhancement at the plasmonic resonance wavelength.

Three to five self-assembled quantum dots (QDs) are a promising candidate for light-absorbing materials used for the so-called fourth generation IR imagers [8]. The absorption band of InAs QDs is varied from mid-wave IR (MWIR, 3-5 $\mu \mathrm{m}$ ) to long-wave IR (LWIR, 8-14 $\mu \mathrm{m}$ ) by manipulating the dot geometries and strain fields $[27,29]$. Strong normal incidence photodetection is possible through intersub-band transitions in QDs due to the three-dimensional confinement of the charge carriers [30]. Reduced electron-phonon scattering in QDs increases the lifetime of photo-excited electrons, leading to high photoconductive gain and high responsivity of QD-based IR photodetectors (QDIPs). Additionally, high temperature operation of QDIPs is feasible owing to the low dark current resulting from a large thermal activation energy, defined as the energy necessary for a bound electron to be excited out of the QD [31,37]. A novel type of intersub-band QDIP using a quantum dots-in-a-well (DWELL) heterostructure has been developed to combine the advantages of quantum wells (QWs) with the advantages of QDs, for instance control over the operating wavelength and normal incidence, respectively [25-28,32-37]. Furthermore, multi-stacking DWELL layers with a uniform dot size and a high dot density is required to improve the absorption quantum efficiency, thereby enabling the realization of high-performance DWELL-based focal plane array (FPA) device (high spatial uniformity and high operability). However, it is challenging to grow such DWELL heterostructures due to strain accumulation and the generation of crystalline defects. Another feasible way to improve the quantum efficiency is to incorporate plasmonic nanostructures into a DWELL-FPA for light absorption 
enhancement in a given volume of QDs, as described above. Besides enhanced light absorption, plasmon-enhanced DWELL detectors provide many advantages such as wavelength controllability, low $1 / f$ noise performance, and high thermal sensitivity $[44,45,59,60]$.

\section{Bias-Tunable Quantum Dots-in-a-Well Pixel Detector}

The quantum dots-in-a-well (DWELL) heterostructure was grown on (001) GaAs substrate by molecular beam epitaxy (MBE) system. As shown in Figure 1a, the DWELL-based single-pixel IR detector (DWELL pixel) consists of a $200 \mathrm{~nm}$-thick GaAs buffer layer, a $50 \mathrm{~nm}$-thick AlAs etch stop layer, a $500 \mathrm{~nm}$-thick n-type GaAs bottom contact layer, active quantum dot (QD) absorption layers, and a 200 nm-thick n-type GaAs top contact layer. The top and bottom contact layers were doped with silicon with a doping concentration of $\mathrm{n}=2 \times 10^{18} \mathrm{~cm}^{-3}$. The active layer consisting of 10 periods of the DWELL structure was sandwiched between the top and bottom contact layers, separated by $50 \mathrm{~nm}$ $\mathrm{Al}_{0.1} \mathrm{Ga}_{0.9} \mathrm{As}$ barriers. The InAs QDs with a nominal thickness of 2 monolayers were embedded in an asymmetric quantum well (QW) structure formed by $50 \mathrm{~nm} \mathrm{Al} l_{0.1} \mathrm{Ga}_{0.9} \mathrm{As} / 7.5 \mathrm{~nm} \mathrm{In} 0.15 \mathrm{Ga}_{0.85} \mathrm{As} / 1.5 \mathrm{~nm}$ $\mathrm{In}_{0.15} \mathrm{Ga}_{0.85} \mathrm{As} / 2 \mathrm{~nm} \mathrm{GaAs} / \mathrm{Al}_{0.1} \mathrm{Ga}_{0.9}$ As layers. The InAs QDs were doped with silicon of a doping concentration of $\sim 1$ electron/dot for high photon absorption.
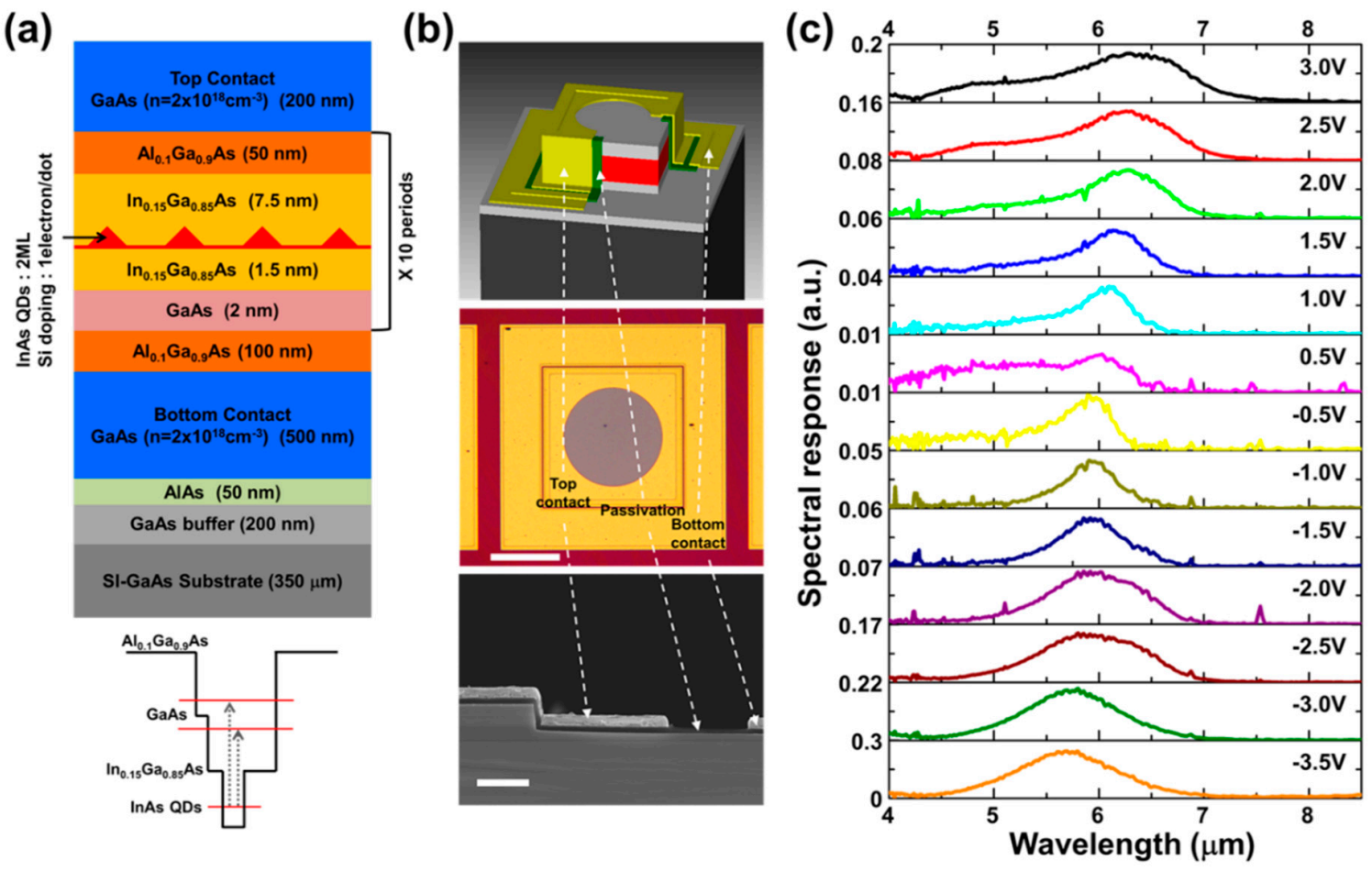

Figure 1. (a) Schematic structure (upper) and conduction band diagram (lower) of bias-dependent dots-in-a-well (DWELL) heterostructure; (b) illustration (upper), optical microscope image (middle), and cross-section view scanning electron microscope (SEM) image (bottom) of the reference DWELL-based single-pixel IR detector. Scale bars are $200 \mu \mathrm{m}$ (middle) and $2 \mu \mathrm{m}$ (lower); (c) bias-dependent spectral responses of DWELL pixel detector at $77 \mathrm{~K}$.

As shown in the upper and middle panels of Figure 1b, the reference DWELL pixel had a mesa structure with a circular aperture of a diameter of $300 \mu \mathrm{m}$. Each mesa was isolated by inductively coupled plasma (ICP) etch with $\mathrm{BCl}_{3}$ chemistry, followed by a wet etch with a citric acid-based solution. After the mesa formation, a $200 \mathrm{~nm}$-thick $\mathrm{Si}_{3} \mathrm{~N}_{4}$ as a surface passivation layer was deposited using plasma enhanced chemical vapor deposition (PECVD). The ohmic contact metals of Ge $(26 \mathrm{~nm}) / \mathrm{Au}$ $(54 \mathrm{~nm}) / \mathrm{Ni}(15 \mathrm{~nm}) / \mathrm{Au}(350 \mathrm{~nm})$ were deposited on the top and bottom contact layers using an e-beam evaporator and annealed at $380^{\circ} \mathrm{C}$ for $1 \mathrm{~min}$. Note that the mesa sidewalls were covered with the top 
contact metals to prevent unwanted light from entering the sidewalls of the DWELL pixel, as clearly seen in the scanning electron microscope (SEM) image of lower panel of Figure 1b. The bias-dependent spectral responses of the DWELL pixel were measured at $77 \mathrm{~K}$ for normal incidence using a Fourier transform infrared (FTIR) spectrometer (Nicolet 5700) and a low-noise current amplifier (Keithley 428). Figure 1c shows that the peak position of the DWELL pixel spectral response is red-shifted continuously from $5.70 \mu \mathrm{m}$ to $6.28 \mu \mathrm{m}$ with increasing the bias voltage from $-3.5 \mathrm{~V}$ to $+3.0 \mathrm{~V}$. This bias tunability of the spectral response is due to the enhanced quantum-confined Stark effect in the asymmetric DWELL structure [61,62]. The intersub-band spacing between the ground state of the QD and the excited state of the InGaAs QW decreases with increasing the applied electric field, as indicated in Figure 1a.

\section{Aperture Shape Variation Effect in the Fabricated Plasmonic Layer on DWELL Pixel Detector}

Prior to the integration of a subwavelength metal hole array (MHA) with DWELL pixel, we designed the MHA to place the MHA-DWELL response peak near the bare DWELL response peak at $+3.0 \mathrm{~V}(\sim 6.3 \mu \mathrm{m}$, Figure 1c) using the 3D full field electromagnetic simulation (CST Microwave studio [63]) based on a finite integration technique (details will be provided in the following section). The geometrical parameters of MHA were found to be $2.0 \mu \mathrm{m}$ for the grating period $(p), 1.0 \mu \mathrm{m}$ for a side length of square hole $(d)$, and $0.1 \mu \mathrm{m}$ for the Au thickness $\left(t_{\mathrm{Au}}\right)$. The designed MHA was fabricated on the aperture of the reference DWELL pixel using a conventional photolithography, e-beam evaporation and lift-off process. Note that the hole-shape discrepancy between the designed and fabricated MHAs is clearly seen in the SEM image, as shown in Figure 2a. The geometrical parameters of the fabricated MHA were found to be $p=2.0 \mu \mathrm{m}, d=1.07 \mu \mathrm{m}, r_{\mathrm{c}}$ (a corner-shape radius) $=\sim 0.33 \mu \mathrm{m}$. All four corners were rounded, which is probably due to imperfections in the fabrication (the optical diffraction limit during the photolithography process [64]). In order to investigate the effect of rounded corners in the MHA layer on the surface plasmon resonance (SPR), we gradually vary the side length $d$ and corner-shape radius $r_{\mathrm{c}}$ and numerically calculate the transmission of MHA on GaAs substrate. In the simulations, a single unit cell, as illustrated in the lower panel of Figure 2b, was simulated. The refractive index of the substrate material (GaAs) was taken as $n_{\mathrm{GaAs}}=3.4$ and the Drude model was used for Au dielectric function [65], with plasma frequency of $\omega_{\mathrm{p}}=1.38 \times 10^{16} \mathrm{~Hz}$ and collision frequency of $\omega_{\mathrm{c}}=5.71 \times 10^{13} \mathrm{~Hz}$.
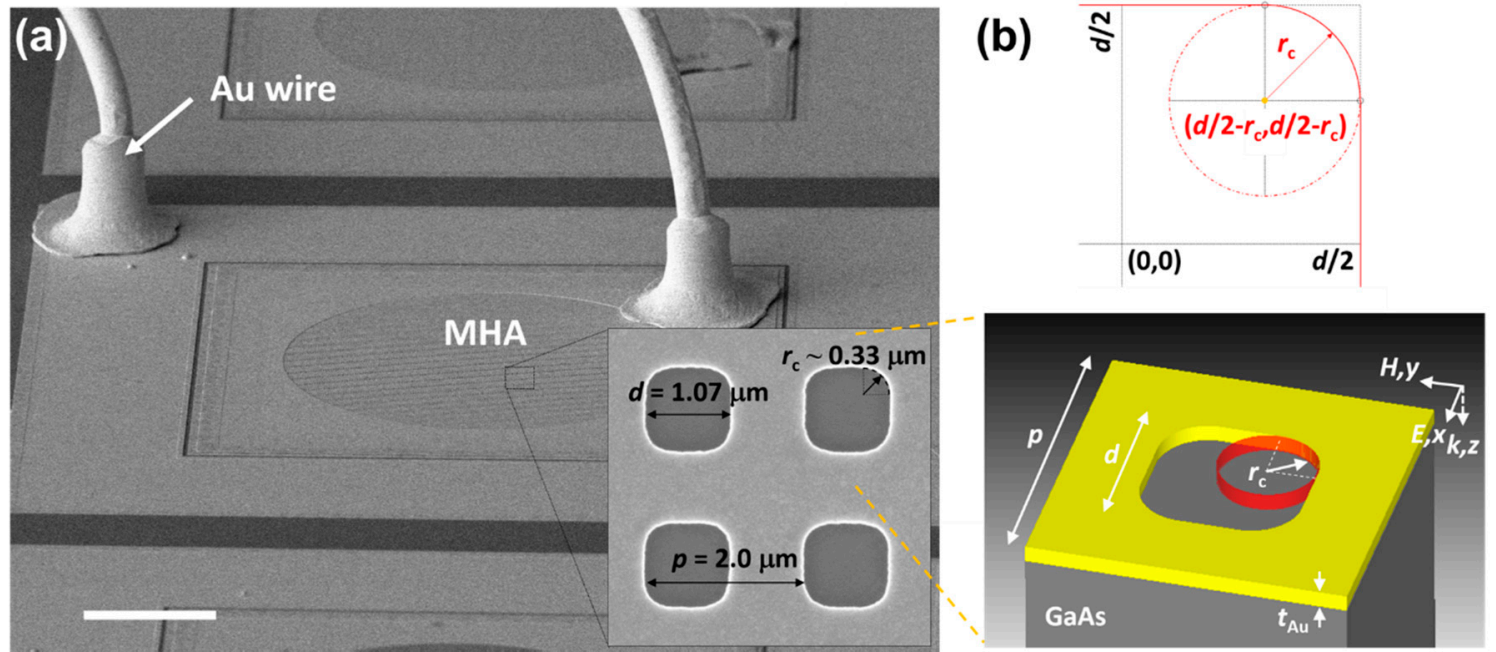

Figure 2. (a) $20^{\circ}$ tilted SEM image of metal hole array (MHA)-layered DWELL pixel detector. Inset shows the magnified square holes with rounded corners: $p=2.0 \mu \mathrm{m}, d=1.07 \mu \mathrm{m}$, and $r_{\mathrm{C}}=\sim 0.33 \mu \mathrm{m}$. Scale bar is $100 \mu \mathrm{m}$; (b) schematic illustration and geometrical parameters of MHA/GaAs unit cell with $r_{\mathrm{c}}$. Here, two extreme cases for the corner-shape radius $r_{\mathrm{C}}$ are $r_{\mathrm{C}}=0 \mu \mathrm{m}$ for a square-shaped hole and $r_{\mathrm{C}} \sim 0.54 \mu \mathrm{m}$ $\left(r_{\mathrm{c}} / d=0.5\right)$ for a circle-shaped hole. In addition, the configuration of polarization $(E / / x)$ and propagation $(k / / z)$ are depicted. 
Figure 3a shows the simulation results for the SPR peak wavelengths (corresponding to the firstand second-order SPR modes at the interface between MHA layer and GaAs substrate) as a function of side length $d$ with a fixed $r_{\mathrm{c}}$ at $0 \mu \mathrm{m}$ (i.e., the hole is square-shaped) in addition to the spectral shift of SPR wavelengths (relative to the side length of $1.0 \mu \mathrm{m}$, i.e., $\lambda_{1}=6.93 \mu \mathrm{m}$ and $\lambda_{2}=4.92 \mu \mathrm{m}$ ) as the side length $d$ changes. As $d$ changes from $1.0 \mu \mathrm{m}$, the first- and second-order SPR wavelengths $\left(\lambda_{1}, \lambda_{2}\right)$ tend to blue-shift; specifically, $\Delta \lambda_{1}=\sim 63 \mathrm{~nm}(-0.91 \%)$ and $\Delta \lambda_{2}=\sim 35 \mathrm{~nm}(-0.72 \%)$ are obtained when $d=0.6 \mu \mathrm{m}\left(\Delta \lambda_{1}=\sim 119 \mathrm{~nm}(-1.72 \%)\right.$ and $\Delta \lambda_{2}=\sim 26 \mathrm{~nm}(-0.52 \%)$ when $\left.d=1.4 \mu \mathrm{m}\right)$. The location and spectral shift of SPR peaks due to varying the corner-shape ratio $\left(r_{\mathrm{c}} / d\right.$ when $\left.d=1 \mu \mathrm{m}\right)$ of the apertures in the MHA layer from 0 (square-shaped hole) to 0.5 (circle-shaped hole) are also shown in Figure $3 \mathrm{~b}$. The $\lambda_{1}$ and $\lambda_{2}$ are blue-shifted by $-0.18 \%(\sim 13 \mathrm{~nm})$ and $-1.36 \%(\sim 67 \mathrm{~nm})$ for increased $r_{\mathrm{c}} / d$ from 0 to 0.5 , respectively. Despite the variations in the side length and the corner-shape ratio, the SPR peak wavelengths of the $\lambda_{1}$ and $\lambda_{2}$ are nearly kept constant within a few percent, $\max \left(\left|\Delta \lambda_{1}\right|\right)=1.72 \%$, $\max \left(\left|\Delta \lambda_{2}\right|\right)=0.72 \%$ for error in the side length $d$, and $\max \left(\left|\Delta \lambda_{1}\right|\right)=0.18 \%, \max \left(\left|\Delta \lambda_{2}\right|\right)=1.36 \%$ for error in the corner-shape ratio $r_{\mathrm{c}} / d\left(r_{\mathrm{c}} / d\right.$ in the unit of $\mu \mathrm{m}$ can be considered as the corner-shape radius $r_{\mathrm{c}}$ because $\left.d=1 \mu \mathrm{m}\right)$. Thus, the position of SPR transmission peaks of the fabricated MHA layer on DWELL pixel detector could be anticipated to spectrally shift less than $\sim 19 \mathrm{~nm}(\sim 6 \mathrm{~nm})$ due to $70 \mathrm{~nm}$ error in the side-length (i.e., $d=1.07 \mu \mathrm{m})$ and $\sim 12 \mathrm{~nm}(\sim 54 \mathrm{~nm})$ resulting from $0.33 \mu \mathrm{m}$ error in the corner-shape radius (i.e., $r_{\mathrm{C}}=0.33 \mu \mathrm{m}$ ) for the first (second)-order SPR as compared with the designed MHA layer $\left(d=1.0 \mu \mathrm{m}\right.$ and $\left.r_{\mathrm{c}}=0 \mu \mathrm{m}\right)$. The SPR excitation wavelength is dominantly determined by the periodicity of the MHA, and also, it is slightly affected by the SPR-scattering-induced phase shift, i.e., depending on the hole geometry [66-70].

The first-order SPR peak transmission $\left(\mathrm{T}_{1}\right)$ and the bandwidth at $50 \%$ of $\mathrm{T}_{1}(\mathrm{FWHM})$ were observed in the range of the corner-shape ratio $r_{\mathrm{c}} / d$ from 0 to 0.5 and the side-length $d$ from $0.6 \mu \mathrm{m}$ to $1.4 \mu \mathrm{m}$, which are presented in Figure 3c,d using the colormaps to clearly show the dependence of hole geometry due to the imperfections in the fabrication. The ratio of hole area $(A)$ to the unit area $\left(p^{2}=2 \mu \mathrm{m} \times 2 \mu \mathrm{m}=4 \mu \mathrm{m}^{2}\right)$ is referred to as the hole-area density $\left(D_{\mathrm{A}}=A / p^{2}\right)$. The black and gray symbols in Figure $3 c$ indicate $\left(r_{\mathrm{c}} / d, d\right)$ the square- and circle-holes arrays with $D_{\mathrm{A}}=0.25$, specifically $(0,1 \mu \mathrm{m})$ and $(0.5, \sim 1.13 \mu \mathrm{m})$, respectively. The solid line represents the curve along which the function $\mathrm{T}_{1}$ of $r_{\mathrm{c}} / d$ and $d$ has $\mathrm{T}_{1}(0,1 \mu \mathrm{m})=0.453$, and the $r_{\mathrm{c}}$ and $d$ values producing the same $D_{\mathrm{A}}$ are indicated as dotted contour lines $\left(D_{\mathrm{A}}=0.25\right.$ for $r_{\mathrm{c}} / d=0$ and $d=1.0 \mu \mathrm{m} ; D_{\mathrm{A}}=0.286$ for $r_{\mathrm{c}} / d=0$ and $d=1.07 \mu \mathrm{m})$. The difference in the first-order SPR transmission peak positions of $(0,1 \mu \mathrm{m})$ and $(0.5, \sim 1.13 \mu \mathrm{m})$ is $\sim 6.24 \mathrm{~nm}$, and the transmission intensity and FWHM of $(0,1 \mu \mathrm{m})$ are found to be $6 \%$ higher and $43 \mathrm{~nm}$ wider than $(0.5, \sim 1.13 \mu \mathrm{m})$. As compared to the designed MHA layer $\left(D_{\mathrm{A}}=0.25\right.$, black symbol), the hole-area density $D_{\mathrm{A}}$ of the fabricated MHA layer on DWELL pixel detector $\left(D_{\mathrm{A}}=\sim 0.26\right.$, red symbol) is $\sim 4 \%$ higher due to increased $d$ and $r_{\mathrm{C}}$ by $70 \mathrm{~nm}$ and $0.33 \mu \mathrm{m}$, respectively; in addition, the first-order SPR transmission intensity of fabricated MHA is slightly decreased by $0.006(\sim 1.3 \%)$, and the FWHM is $\sim 9.1 \%$ narrower, which may come from the change in the effective dielectric property in the Au film perforated with subwavelength holes [66-70]. The simulation results in Figure 3 clearly show that the fabrication-induced hole-shape variation in the MHA has little impact on the SPR characteristics, e.g., $\lambda_{1}$ (spectral position of SPR peak), the bandwidth, and $\mathrm{T}_{1}$ (SPR-enhanced transmission). The SPR-related simulations (associated with the fabrication-induced imperfections) drawn here will be of great importance in the next section, because they are closely correlated to modifying the spectral selectivity and to enhancing the coupling to the active layer of DWELL pixel detector. 
(a)

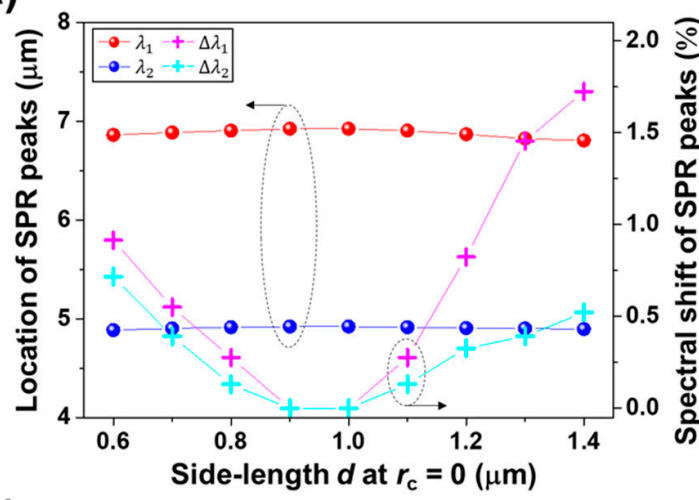

(b)

(c)
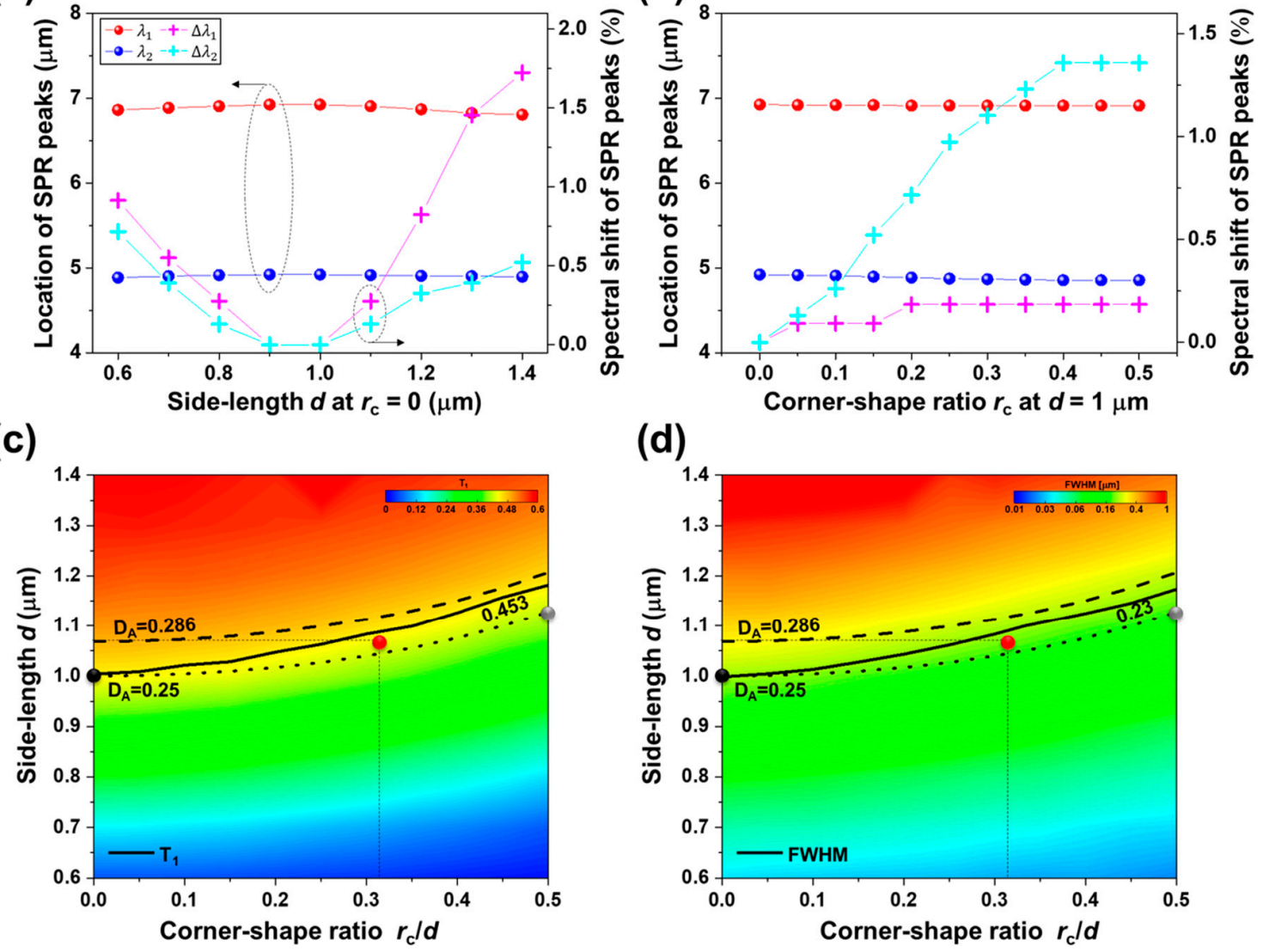

(d)

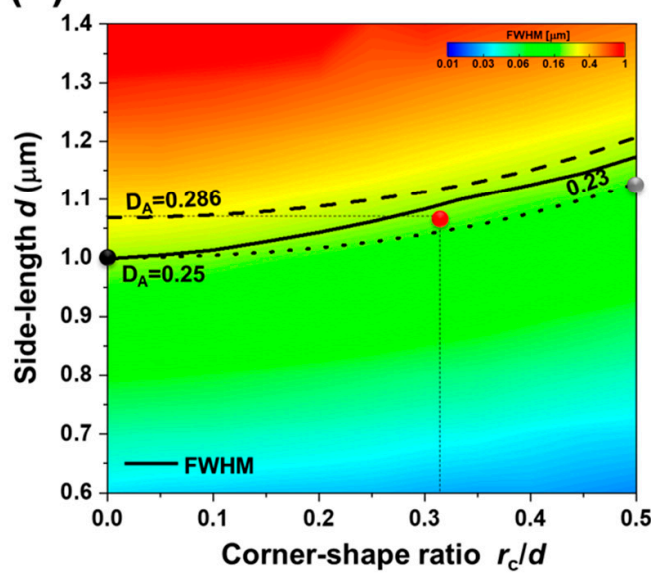

Figure 3. The location and spectral shift of peak transmission at the first- and second-order SPR modes for MHA/GaAs structure as a function of (a) the side length $d$ with a fixed $r_{\mathrm{c}}$ at 0 ; (b) the ratio of corner-shape radius to the side length, $r_{\mathrm{c}} / d$ with $d=1 \mu \mathrm{m}$. The first- and second-order SPR peak wavelengths $\left(\lambda_{1}\right.$ and $\left.\lambda_{2}\right)$ and the spectral shift of SPR-transmission peaks $\left(\Delta \lambda_{1}\right.$ and $\left.\Delta \lambda_{2}\right)$ are represented by the red, blue, magenta, and cyan symbols, respectively. The colormaps of (c) transmission peak intensity; (d) the bandwidth at 50\% of the peak transmission (FWHM) at $\lambda_{1}=6.93 \mu \mathrm{m}$ as a function of $d(0.6 \mu \mathrm{m} \leq d \leq 1.4 \mu \mathrm{m})$ and $r_{\mathrm{c}} / d\left(0 \leq r_{\mathrm{d}} / d \leq 0.5\right)$.

\section{Underlying Mechanism of Plasmonic Layered DWELL Pixel Detector}

Figure $4 \mathrm{~b}$ shows the measured spectral response of the DWELL pixel (without MHA layer, referring to 'DWELL') and MHA-layered DWELL pixel (with MHA layer, referring to 'MHA-DWELL') at a bias of $+3.0 \mathrm{~V}$ and a temperature of $77 \mathrm{~K}$. The bandwidth at $50 \%$ of the peak DWELL response is found to be $\sim 1440 \mathrm{~nm}$, i.e., $\left|\lambda_{\mathrm{L}}-\lambda_{\mathrm{R}}\right|$, where $\lambda_{\mathrm{L}}=\sim 5.47 \mu \mathrm{m}$ and $\lambda_{\mathrm{R}}=\sim 6.91 \mu \mathrm{m}$ at $50 \%$ of the peak DWELL response intensity of $\sim 0.085$ (the peak DWELL response was detected at $\sim 6.29 \mu \mathrm{m}$ ). The peak MHA-DWELL response was observed at the wavelength of $\lambda_{1} \sim 6.39 \mu \mathrm{m}$ and FWHM was found to be $\sim 610 \mathrm{~nm}$, which is attributed to the fourfold degenerate first-order SPR mode (note that unpolarized FTIR beam was incident to measure the spectral responses of DWELL and MHA-DWELL). In order to investigate the effect of MHA layer (SPR) to the bandwidth (FWHM) reduction, the electric field distributions in $x$ (parallel to the incident polarization) and $z$ (along the MBE growth direction) directions were simulated at $\lambda_{\mathrm{L}}(5.47 \mu \mathrm{m}), \lambda_{1}(6.39 \mu \mathrm{m})$, and $\lambda_{\mathrm{R}}(6.91 \mu \mathrm{m})$ when an $x$-polarized plane wave is normally incident to the apertures of the DWELL and the MHA-DWELL. The schematic illustrations of the simplified unit cells of DWELL and MHA-DWELL are shown in Figure 4a,c, which were used in the simulation. The DWELL and MHA-DWELL consist of the multiple layers for top contact $(0.2 \mu \mathrm{m})$, active $(0.71 \mu \mathrm{m})$, bottom contact $(0.5 \mu \mathrm{m})$, etch stop $(0.05 \mu \mathrm{m})$ as well as MHA layer $(p=2.0 \mu \mathrm{m}$, $\left.d=1.07 \mu \mathrm{m}, r_{\mathrm{c}}=0.33 \mu \mathrm{m}, t_{\mathrm{Au}}=0.105 \mu \mathrm{m}\right)$. Figure 4e,f show the simulated $x$ and $z$ component-electric 
field $\left(\left|E_{\mathrm{x}}\right|\right.$ and $\left.\left|E_{\mathrm{z}}\right|\right)$ distributions for MHA-DWELL in a $x z$-plane through the center of unit cell. We also present the simulated $\left|E_{\mathrm{x}}\right|$ distribution of DWELL to clearly see the difference due to the presence of the MHA layer (SPR effect), as plotted in Figure $4 \mathrm{~d}$. Note that $\left|E_{\mathrm{y}}\right| \approx 0$ and $\left|E_{\mathrm{z}}\right| \approx 0$ for DWELL and $\left|E_{\mathrm{y}}\right| \approx 0$ for MHA-DWELL. For DWELL, we can observe the uniformly distributed $\left|E_{\mathrm{x}}\right|$ over the whole active area (i.e., $E_{\mathrm{x}}(x, y, z)=E_{\mathrm{X}}(z)$, where $\left.0.2 \mu \mathrm{m} \leq z \leq 0.91 \mu \mathrm{m}\right)$ and propagating $E_{\mathrm{x}}$ along $z$-direction. Contrary to the DWELL, when the MHA (integrated with DWELL) interacts with the incident EM wave with a wavelength of $\lambda_{\mathrm{L}}, \lambda_{1}$, and $\lambda_{\mathrm{R}}$, the strong $\left|E_{\mathrm{x}}\right|$ and $\left|E_{\mathrm{Z}}\right|$ are observed at the edges of aperture in the MHA, as shown in Figure 4e,f. The highest value of $\left|E_{\mathrm{k}}(\lambda)\right|$ at the hole edges in the wavelength range of interest is found at the wavelength of $\lambda_{1}\left(\left|E_{\mathrm{k}}\left(\lambda_{1}\right)\right|>\left|E_{\mathrm{k}}\left(\lambda_{\mathrm{R}}\right)\right|>\left|E_{k}\left(\lambda_{\mathrm{L}}\right)\right|\right.$, where $k=x$ or $\left.z\right)$, which is ascribed to the electric current on the MHA generated by the first-order SPR. In the following discussion, the excited electric field $\left(\left|E_{z}\right|\right)$ due to the SPR in the MHA-DWELL will be greatly important role to enhance the DWELL response intensity (photocurrent) in addition to changing the bandwidth (FWHM) of photocurrent spectral response of DWELL.

The total absorption in each layer of the considered DWELL (or MHA-DWELL) can be calculated using Equation (1), where $i$ 's are top / bottom contact layers, active layer, and MHA; $c_{0}$ is the speed of light; $\varepsilon_{i}^{\prime \prime}(\lambda)$ is the imaginary part of dielectric constant; $\left|E_{i, \mathrm{x}}(\lambda)\right|^{2},\left|E_{i, \mathrm{y}}(\lambda)\right|^{2}$ and $\left|E_{i, \mathrm{z}}(\lambda)\right|^{2}$ are the $x, y$, and $z$ components of the electric field intensity over $i$-layer; $\eta \sim 7$ is used to account for anisotropic dielectric constant in the active layer.

$$
A_{i}(\lambda)=\int \frac{2 \pi c_{0} \cdot \varepsilon_{i}^{\prime \prime}(\lambda)}{\lambda} \cdot\left(\left|E_{i, x}(\lambda)\right|^{2}+\left|E_{i, y}(\lambda)\right|^{2}+\eta\left|E_{i, z}(\lambda)\right|^{2}\right) d V_{i}
$$

Figure $4 \mathrm{~g}$,h show $A_{i}(\lambda) /\left(2 \pi c_{0} \varepsilon_{i}^{\prime \prime}(\lambda) / \lambda\right)$ to clearly see the change of total electric field intensity in the different layers of DWELL and MHA-DWELL due to the presence of MHA layer. The volume integral of electric field intensity over the whole active region of DWELL (Figure $4 \mathrm{~g}$ ) is likely to be independent of the wavelength, however the first- and second-order SPRs are not only found in the active layer of MHA-DWELL but also observed in other layers constituting MHA-DWELL, as shown in Figure $4 \mathrm{~h}$. The calculated absorption spectrum is used to evaluate the spectral DWELL (MHA-DWELL) response $R(\lambda) \approx \alpha \cdot A_{\text {act }}(\lambda)$. Here, $\alpha=\left(e^{-} \cdot \lambda\right) /\left(h \cdot c_{0}\right)$, where $e^{-}$is the electric charge, $h$ is the Planck constant, and $A_{\text {act }}$ is the total absorption in the active layer of DWELL (MHA-DWELL), as seen in Figure $4 \mathrm{j}, \mathrm{k}$. For simplicity in the calculation, we assumed that an electron-hole pair is collected for each photon absorbed in the active layer. 

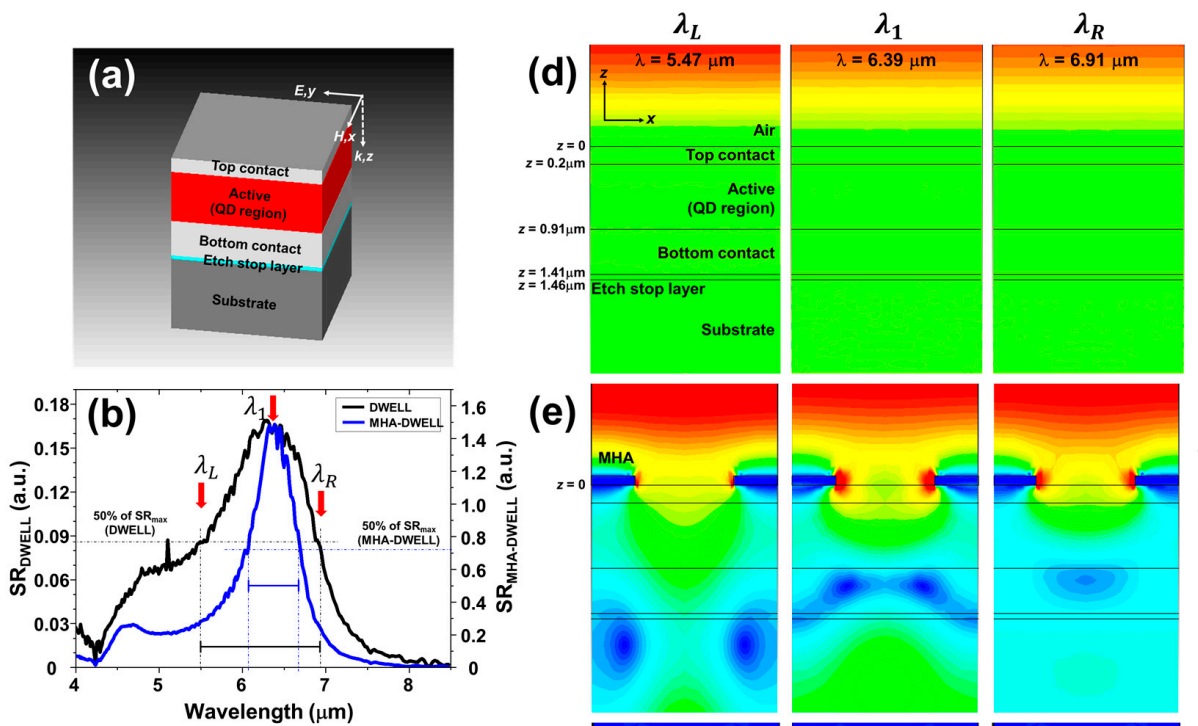

(e)
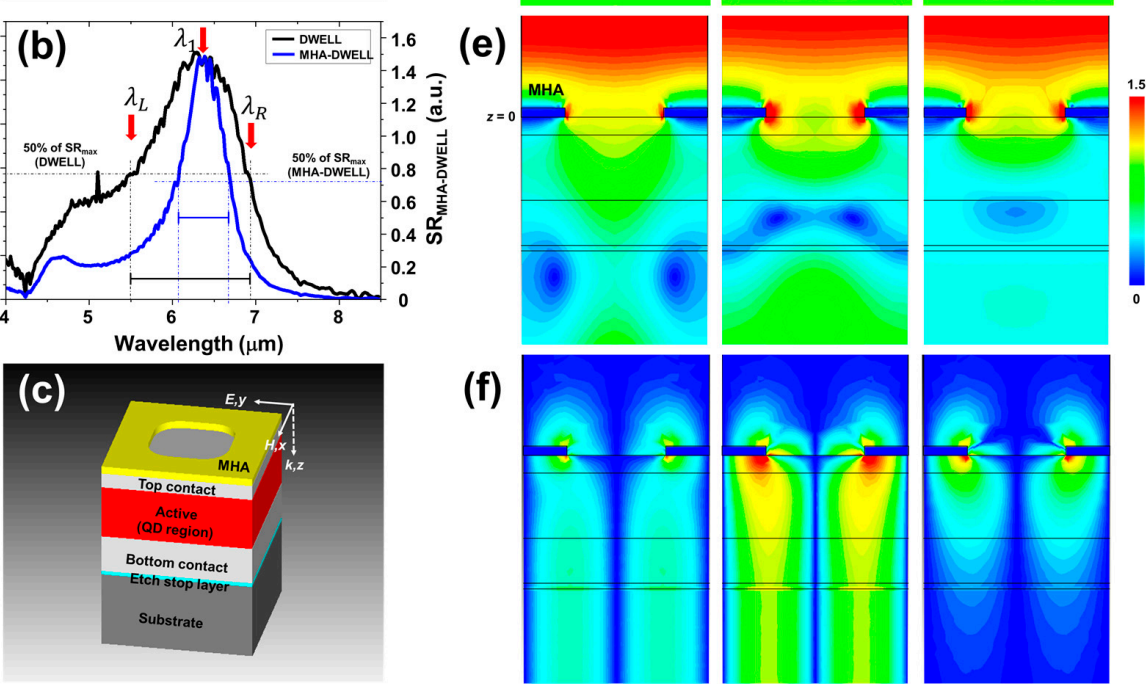

(f)
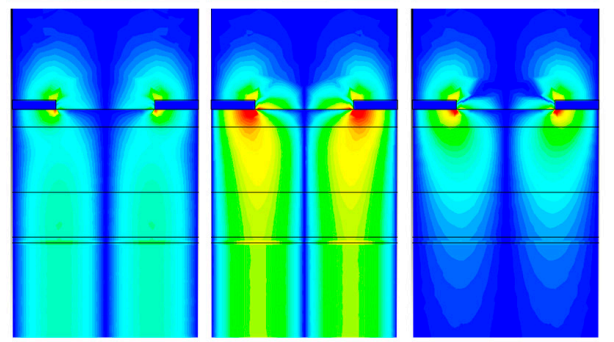

(g)

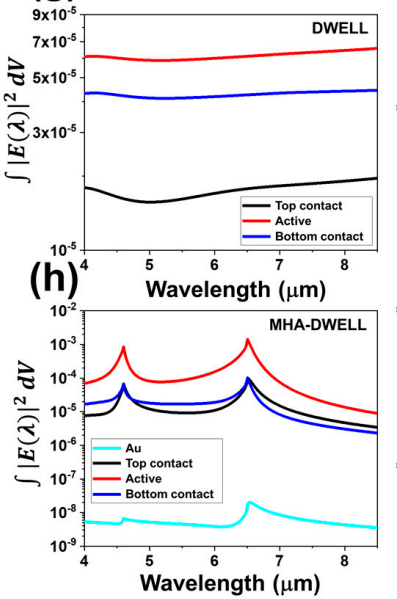

(i)

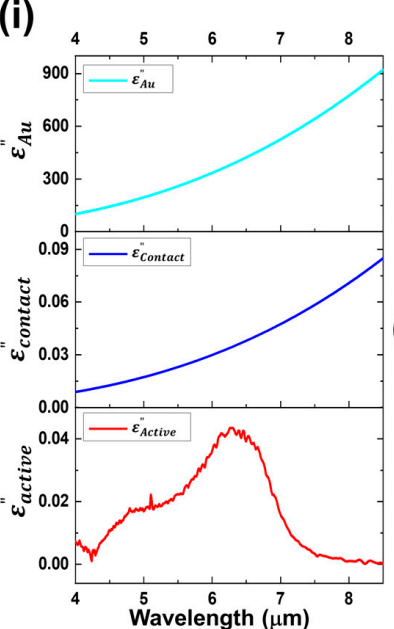

(j)

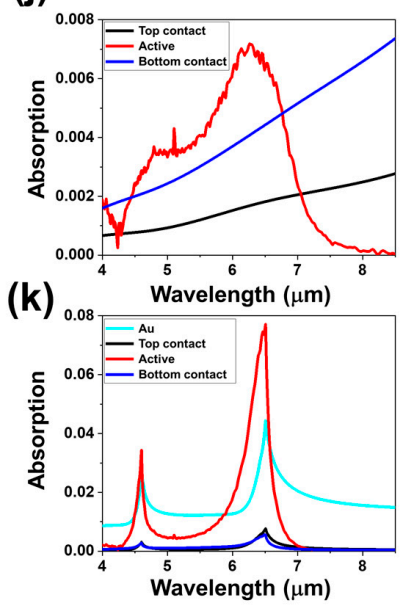

Figure 4. $(a, c)$ The schematic illustrations of the simplified unit cells of DWELL and MHA-DWELL pixel detectors; (b) measured spectral response of DWELL and MHA-DWELL pixel detectors at a bias of $+3.0 \mathrm{~V}$ and a temperature of $77 \mathrm{~K}$. The simulated $x$ component-electric field $\left|E_{\mathrm{x}}\right|$ for DWELL and $\left|E_{\mathrm{x}}\right|$ and $\left|E_{\mathrm{z}}\right|$ for MHA-DWELL at the wavelengths of $\lambda_{\mathrm{L}}(5.47 \mu \mathrm{m}), \lambda_{1}(6.39 \mu \mathrm{m}), \lambda_{\mathrm{R}}(6.91 \mu \mathrm{m})$ in a $x z$-plane through the center of unit cell; (d) $\left|E_{\mathrm{x}}(x, 0, z)\right|$ for DWELL; (e) $\left|E_{\mathrm{x}}(x, 0, z)\right| ;(\mathbf{f})\left|E_{\mathrm{Z}}(x, 0, z)\right|$ for MHA-DWELL. The volume integral of total electric field intensity for all layers constituting (g) DWELL; (h) MHA-DWELL; (i) the imaginary part of dielectric constant in the contact layers (top and bottom), $\mathrm{Au}$, and the active layer. The total absorption of each layer in (j) DWELL; (k) MHA-DWELL, which are easily calculated by multiplying the layer-volume integral of electric field intensity by $\left(2 \pi C_{0} \cdot \varepsilon_{i}^{\prime \prime}(\lambda) / \lambda\right)$ (for i-layer, $A_{i}(\lambda)=\left(2 \pi c_{0} \cdot \varepsilon_{i}^{\prime \prime}(\lambda) / \lambda\right) \times \int\left|E_{x}(\lambda)\right|^{2} d V$ for DWELL and $A_{i}(\lambda)=\left(2 \pi c_{0} \cdot \varepsilon_{i}^{\prime \prime}(\lambda) / \lambda\right) \times \int\left(\left|E_{x}(\lambda)\right|^{2}+\eta\left|E_{z}(\lambda)\right|^{2}\right) d V$ for MHA-DWELL). Note that $\eta=7$ is applied for the active layer of MHA-DWELL to bring the characteristic of quantum dot (QD)-shape-dependent sensitivity, i.e., the electric field along the growth direction is dominantly interacting with the QDs. 


\section{Electro-Optical Characterization of Plasmonic Layered Bias-Tunable DWELL Pixel Detector}

Figure 5a exhibits the measured spectral responses of the MHA-DWELL pixel detector by applying the bias between $-3.5 \mathrm{~V}$ and $+3.0 \mathrm{~V}$ with a step of $0.5 \mathrm{~V}$ at a temperature of $77 \mathrm{~K}$. We can see clearly the bias tunability of the DWELL response peak wavelength, i.e., the peak wavelength of the measured spectral response of DWELL pixel detector (black dash-line) is gradually shifted toward longer wavelengths with increasing the bias from $-3.5 \mathrm{~V}$ to $+3.0 \mathrm{~V}$, which results from enhanced quantum-confined Stark effect in the asymmetric DWELL structure. On the other hand, the response peaks of the MHA-DWELL pixel detector (red dash-line) are found at the wavelength of $\sim 6.4 \mu \mathrm{m}$ despite changing the bias, which is attributed to improving the absorption in the active layer at the SPR wavelength, as seen in Figure $4 \mathrm{j}, \mathrm{k}$. In more detail, this improved absorption in the active layer is due to the enhanced $z$ component electric field caused by the presence of MHA layer in the MHA-DWELL pixel detector. Figure 4 shows that the response intensity of DWELL pixel detector at a bias of $+3.0 \mathrm{~V}$ can be resultingly increased. However, the enhanced MHA-DWELL response was also measured at a bias of $3.0 \mathrm{~V}$, and thus, we consider the effect of change in the bias, i.e., in case of the spacing between the SPR wavelength of the designed MHA and the peak wavelength of DWELL at the different bias. Note that MHA was designed to locate the MHA-DWELL response peak close to the DWELL response peak at $+3.0 \mathrm{~V}$ as explained in the previous section, "Fabricated plasmonic layer on DWELL pixel detector". Figure $5 \mathrm{~b}$ shows the measured response peak wavelengths for MHA-DWELL (red hollow-square) and DWELL pixel detectors (black hollow-square), and the ratio of peak response of MHA-DWELL to DWELL at the first-order SPR wavelength $(\sim 6.4 \mu \mathrm{m})$. The overall agreement between experimental results and the simulated enhancement ratios at the first SPR wavelength in the bias-range from $-3.0 \mathrm{~V}$ to $+3.5 \mathrm{~V}$ is apparent from Figure $5 \mathrm{~b}$. We find that the enhancement ratios (calculated using the measured detector responses) are obtained with $\sim 8.3(-3.5 \mathrm{~V}), \sim 9(-3.0 \mathrm{~V})$, $\sim 10(-2.5 \mathrm{~V}), \sim 13.7(-2.0 \mathrm{~V}) \sim 16.8 \mathrm{~V}(-1.5 \mathrm{~V}), \sim 17.8(-1 \mathrm{~V}), \sim 30.4(-0.5 \mathrm{~V}), \sim 12(+0.5 \mathrm{~V}), \sim 10.1(+1 \mathrm{~V})$, $\sim 9.1(+1.5 \mathrm{~V}), \sim 8.3(+2.0 \mathrm{~V}), \sim 8.4(+2.5 \mathrm{~V})$, and $\sim 8.4(+3.0 \mathrm{~V})$. Discrepancies of response-peak wavelength and enhancement ratio in the range of small bias are probably due to the low intensity of detector response and the alignment in the electro-optical measurement. Figure $5 \mathrm{a}, \mathrm{b}$ clearly demonstrate that the integration of MHA layer onto the DWELL pixel detector (MHA-DWELL) can significantly improve the DWELL sensitivity and realize the wavelength-sensitive IR detector with a narrower bandwidth, as compared to a bare DWELL detector. 

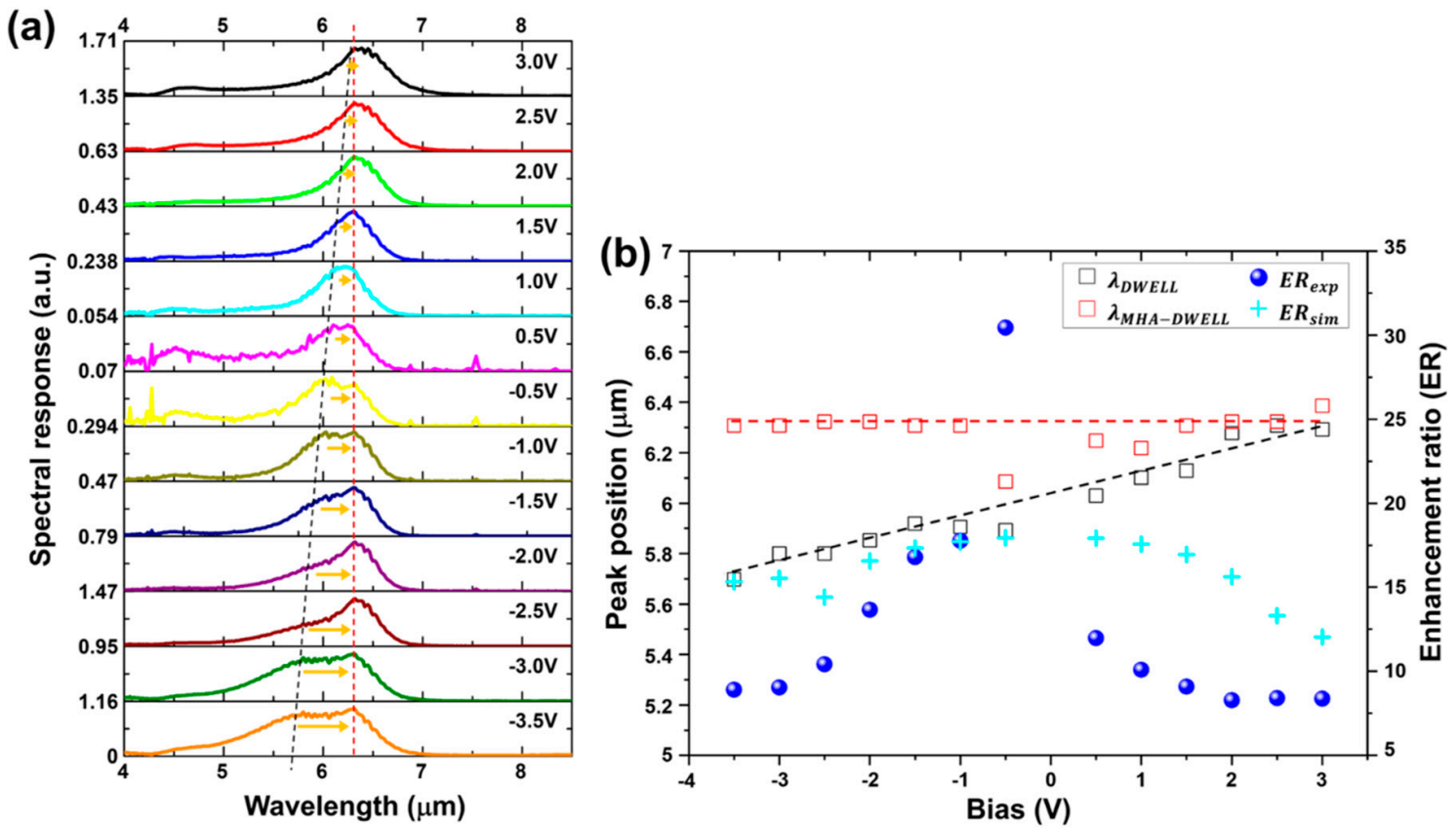

Figure 5. (a) Experimental spectral responses of MHA-DWELL pixel detector with applying the bias voltage from $-3.5 \mathrm{~V}$ to $+3.0 \mathrm{~V}$ at $77 \mathrm{~K}$. Red (black) dash line indicates the peak position of MHA-DWELL (DWELL) response; (b) measured response-peak wavelengths for MHA-DWELL (red, hollow square) and DWELL (black, hollow square), and the ratio of peak response of MHA-DWELL to DWELL (measurement: blue sphere; simulation: cyan cross).

\section{Conclusions}

The results outlined here illustrate the potential of plasmonic resonance in a metal layer perforated with a two-dimensional subwavelength hole array for improving the infrared (IR) detector sensitivity and modifying the detector spectral response as desired in order to fully benefit from algorithmic spectrometry that is at the heart of next generation spectral IR sensor, just as the human eye does. Uniquely, we have demonstrated numerically and experimentally the capability for the control over the shape of bias-tunable InAs/InGaAs quantum-dots-in-a-well (DWELL) detector responses as well as the detector responsivity enhancement by integrating a fixed plasmonic structure. The measured response peaks of the plasmonic DWELL detector are found at the plasmonic resonance wavelength of $\sim 6.4 \mu \mathrm{m}$, while the peak position of the DWELL detector response is shifted continuously from $\sim 5.70 \mu \mathrm{m}$ to $\sim 6.30 \mu \mathrm{m}$ with increasing the bias voltage from $-3.5 \mathrm{~V}$ to $+3.0 \mathrm{~V}$. In addition, the ratio of peak response of plasmonic DWELL to DWELL at the plasmonic wavelength of $\sim 6.4 \mu \mathrm{m}$ is obtained in a range from $\sim 8.3$ to $\sim 30.4$. The spectral-shaping and photoresponse enhancement are achieved by the anisotropic dielectric constants of DWELL absorber and the electric field in the direction along the growth direction due to the excitation of surface plasmon resonance. The comprehensive set of data gained from computational and theoretical studies provides an insight into fundamental principles and design trade-offs of plasmonic architectures for realizing an efficient and easy-to-modify DWELL (or QD)-based IR detector.

Author Contributions: Conceptualization, J.H. and Z.K.; formal analysis, J.H., J.J., and Z.K.; investigation, J.H., J.J., and Z.K.; resources, D.-K.K., A.U., E.K.K., and S.J.L.; writing-original draft preparation, J.H., Y.K., J.O.K., and Z.K.; writing-review and editing, J.H., Z.K., E.K.K., and S.J.L.; supervision, Z.K., E.K.K., and S.J.L.; funding acquisition, S.J.L. All authors have read and agreed to the published version of the manuscript.

Funding: Korea Research Institute of Standards and Science (KRISS-2020-GP2020-0011); Nano Material Fundamental Technology Development Program (2018069993) through the National Research Foundation of Korea (NRF) funded by the Ministry of Science and ICT; AOARD Grant FA2386-18-1-4021 funded by the US government (AFOSR/AOARD). The AFRL portion of this work was supported by the AOARD Grant FA2386-18-1-4104 funded by the U.S. government (AFOSR/AOARD). 
Conflicts of Interest: The authors declare no conflict of interest.

\section{References}

1. Goetz, A.F.H.; Vane, G.; Solomon, J.E.; Rock, B.N. Imaging spectrometry for earth remote sensing. Science 1985, 228, 1147-1153. [CrossRef]

2. Green, R.O.; Eastwood, M.L.; Sarture, C.M.; Chrien, T.G.; Aronsson, M.; Chippendale, B.J.; Faust, J.A.; Pavri, B.E.; Chovit, C.J.; Solis, M.; et al. Imaging spectroscopy and the airborne visible/infrared imaging spectrometer (AVIRIS). Remote Sens. Environ. 1998, 65, 227-248. [CrossRef]

3. Roggo, Y.; Edmond, A.; Chalus, P.; Ulmschneider, M. Infrared hyperspectral imaging for qualitative analysis of pharmaceutical solid forms. Anal. Chim. Acta. 2005, 535, 79-87. [CrossRef]

4. Ratches, J.A. Review of current aided/automatic target acquisition technology for military target acquisition tasks. Opt. Eng. 2011, 50, 072001. [CrossRef]

5. Salzer, R.; Steiner, G.; Mantsch, H.H.; Mansfield, J.; Lewis, E.N. Infrared and Raman imaging of biological and biomimetic samples. Fresenius J. Anal. Chem. 2000, 366, 712-726. [CrossRef] [PubMed]

6. Hackwell, J.A.; Warren, D.W.; Bongiovi, R.P.; Hansel, S.J.; Hayhurst, T.L.; Mabry, D.J.; Sivjee, M.G.; Skinner, J.W. LWIR/MWIR imaging hyperspectral sensor for airborne and ground-based remote sensing. Proc. SPIE Int. Soc. Opt. Eng. 1996, 2819, 102-107.

7. Lucey, P.G.; Horton, K.A.; Williams, T. Performance of a long-wave infrared hyperspectral imager using a Sagnac interferometer and an uncooled microbolometer array. Appl. Opt. 2008, 47, F107-F113. [CrossRef] [PubMed]

8. Martyniuk, P.; Antoszewski, J.; Martyniuk, M.; Faraone, L.; Rogalski, A. New concepts in infrared photodetector designs. Appl. Phys. Rev. 2014, 1, 041102. [CrossRef]

9. Wässle, H. Parallel processing in the mammalian retina. Nat. Rev. Neurosci. 2004, 5, 747-757. [CrossRef]

10. Roska, B.; Werblin, F. Vertical interactions across ten parallel, stacked representations in the mammalian retina. Nature 2001, 410, 583-587. [CrossRef]

11. Jang, W.-Y.; Hayat, M.M.; Tyo, J.S.; Attaluri, R.S.; Vandervelde, T.E.; Sharma, Y.D.; Shenoi, R.; Stintz, A.; Cantwell, E.R.; Bender, S.C.; et al. Demonstration of bias-controlled algorithmic tuning of quantum dots in a well (DWELL) midIR detectors. IEEE J. Quantum Electron. 2009, 45, 674-683. [CrossRef]

12. Vines, P.; Tan, C.H.; David, J.P.R.; Attaluri, R.S.; Vandervelde, T.E.; Krishna, S.; Jang, W.-Y.; Hayat, M.M. Versatile spectral imaging with an algorithm-based spectrometer using highly tuneable quantum dot infrared photodetectors. IEEE J. Quantum Electron. 2011, 47, 190-197. [CrossRef]

13. Krishna, S.; Hayat, M.; Tyo, J.; Jang, W.-Y. STC.UNM, Arizona Board of Regents. Infrared Retina. U.S. Patent US 8,071,945B2, 6 December 2011.

14. De Iacovo, A.; Venettacci, C.; Giansante, C.; Colace, L. Narrowband colloidal quantum dot photodetectors for wavelength measurement applications. Nanoscale 2020, 12, 10044-10050. [CrossRef] [PubMed]

15. Craig, B.J.; Meng, J.; Shrestha, V.R.; Cadusch, J.J.; Crozier, K.B. Mid-to long-wave infrared computational spectroscopy using a subwavelength coaxial aperture array. Sci. Rep. 2019, 9, 1-11. [CrossRef] [PubMed]

16. Bao, J.; Bawendi, M.G. A colloidal quantum dot spectrometer. Nature 2015, 523, 67-70. [CrossRef] [PubMed]

17. Sakoglu, Ü.; Hayat, M.M.; Tyo, J.S.; Dowd, P.; Annamalai, S.; Posani, K.T.; Krishna, S. Statistical adaptive sensing by detectors with spectrally overlapping bands. Appl. Opt. 2006, 45, 7224-7234. [CrossRef]

18. Sakoglu, Ü.; Wang, Z.; Hayat, M.M.; Tyo, J.S.; Annamalai, S.; Dowd, P.; Krishna, S. Quantum dot detectors for mid-infrared sensing: Bias-controlled spectral tuning and matched filtering. Proc. SPIE Int. Soc. Opt. Eng. 2004, 5593, 396-407.

19. Sakoglu, Ü.; Tyo, J.S.; Hayat, M.M.; Raghavan, S.; Krishna, S. Spectrally adaptive infrared photodetectors with bias-tunable quantum dots. J. Opt. Soc. Am. B 2004, 21, 7-17. [CrossRef]

20. Jang, W.-Y.; Ku, Z.; Urbas, A.; Derov, J.; Noyola, M.J. Plasmonic Super-pixel Sensor for Compressive Spectral Sensing. IEEE Trans. Geosci. Remote Sens. 2005, 53, 3471-3480. [CrossRef]

21. Jang, W.-Y.; Ku, Z.; Jeon, J.; Kim, J.O.; Lee, S.J.; Park, J.; Noyola, M.J.; Urbas, A. Experimental demonstration of adaptive infrared multispectral imaging using plasmonic filter array. Sci. Rep. 2016, 6, 1-9. [CrossRef]

22. Ebbesen, T.W.; Lezec, H.J.; Ghaemi, H.F.; Thio, T.; Wolff, P.A. Extraordinary optical transmission through sub-wavelength hole arrays. Nature 1998, 391, 667-669. [CrossRef] 
23. Barnes, W.L.; Dereux, A.; Ebbesen, T.W. Surface plasmon subwavelength optics. Nature 2003, 424, 824-830. [CrossRef] [PubMed]

24. Genet, C.; Ebbesen, T.W. Light in tiny holes. Nat. Rev. Mater. 2010, 445, 205-212.

25. Krishna, S. Quantum dots-in-a-well infrared photodetectors. J. Phys. D Appl. Phys. 2005, 38, 2142. [CrossRef]

26. Liu, G.T.; Stintz, A.; Li, H.; Newell, T.C.; Gray, A.L.; Varangis, P.M.; Malloy, K.J.; Lester, L.F. The influence of quantum-well composition on the performance of quantum dot lasers using InAs-InGaAs dots-in-a-well (DWELL) structures. IEEE J. Quantum Electron. 2000, 36, 1272-1279. [CrossRef]

27. Raghavan, S.; Rotella, P.; Stintz, A.; Fuchs, B.; Krishna, S.; Morath, C.; Cardimona, D.A.; Kennerly, S.W. High-responsivity, normal-incidence long-wave infrared $(\lambda \sim 7.2 \mu \mathrm{m}) \mathrm{InAs} / \mathrm{In}_{0.15} \mathrm{Ga}_{0.85} \mathrm{As}$ dots-in-a-well detector. Appl. Phys. Lett. 2002, 81, 1369-1371. [CrossRef]

28. Barve, A.V.; Lee, S.J.; Noh, S.K.; Krishna, S. Review of current progress in quantum dot infrared photodetectors. Laser Photonics Rev. 2010, 4, 738-750. [CrossRef]

29. Kim, E.-T.; Chen, Z.; Madhukar, A. Tailoring detection bands of InAs quantum-dot infrared photodetectors using $\mathrm{In}_{\mathrm{x}} \mathrm{Ga}_{1-\mathrm{x}}$ As strain-relieving quantum wells. Appl. Phys. Lett. 2001, 79, 3341-3343. [CrossRef]

30. Phillips, J.; Kamath, K.; Bhattacharya, P. Far-infrared photoconductivity in self-organized InAs quantum dots. Appl. Phys. Lett. 1998, 72, 2020-2022. [CrossRef]

31. Tsao, S.; Lim, H.; Zhang, W.; Razeghi, M. High operating temperature $320 \times 256$ middle-wavelength infrared focal plane array imaging based on an In As/InGaAs/InAlAs/InP quantum dot infrared photodetector. Appl. Phys. Lett. 2007, 90, 201109. [CrossRef]

32. Höglund, L.; Asplund, C.; Wang, Q.; Almqvist, S.; Malm, H.; Petrini, E.; Andersson, J.Y.; Holtz, P.O.; Pettersson, H. Origin of photocurrent in lateral quantum dots-in-a-well infrared photodetectors. Appl. Phys. Lett. 2006, 88, 213510. [CrossRef]

33. Jolley, G.; Fu, L.; Tan, H.H.; Jagadish, C. Properties of $\mathrm{In}_{0 .}{ }_{5} \mathrm{Ga}_{0.5} \mathrm{As} / \mathrm{GaAs} / \mathrm{Al}_{0.2} \mathrm{Ga}_{0.8}$ As quantum-dots-in-a-well infrared photodetectors. J. Phys. D Appl. Phys. 2009, 42, 095101. [CrossRef]

34. Kim, J.O.; Sengupta, S.; Barve, A.V.; Sharma, Y.D.; Adhikary, S.; Lee, S.J.; Noh, S.K.; Allen, M.S.; Allen, J.W.; Chakrabarti, S.; et al. Multi-stack InAs/InGaAs sub-monolayer quantum dots infrared photodetectors. Appl. Phys. Lett. 2013, 102, 011131. [CrossRef]

35. Aivaliotis, P.; Vukmirović, N.; Zibik, E.A.; Cockburn, J.W.; Indjin, D.; Harrison, P.; Groves, C.; David, J.P.R.; Hopkinson, M.; Wilson, L.R. Stark shift of the spectral response in quantum dots-in-a-well infrared photodetectors. J. Phys. D Appl. Phys. 2007, 40, 5537. [CrossRef]

36. Kim, J.O.; Ku, Z.; Kazemi, A.; Urbas, A.; Kang, S.W.; Noh, S.K.; Lee, S.J.; Krishna, S. Effect of barrier on the performance of sub-monolayer quantum dot infrared photodetectors. Opt. Mater. Express 2014, 4, 198-204. [CrossRef]

37. Krishna, S. Quantum dots-in-a-well infrared photodetectors. Infrared Phys. Technol. 2005, 47, $153-163$. [CrossRef]

38. Chang, C.C.; Sharma, Y.D.; Kim, Y.S.; Bur, J.A.; Shenoi, R.V.; Krishna, S.; Huang, D.; Lin, S.-Y. A surface plasmon enhanced infrared photodetector based on InAs quantum dots. Nano Lett. 2010, 10, 1704-1709. [CrossRef]

39. Lee, S.J.; Ku, Z.; Barve, A.; Montoya, J.; Jang, W.-Y.; Brueck, S.R.J.; Sundaram, M.; Reisinger, A.; Krishna, S.; Noh, S.K. A monolithically integrated plasmonic infrared quantum dot camera. Nat. Commun. 2011, 2, 1-6. [CrossRef]

40. Ku, Z.; Jang, W.Y.; Zhou, J.; Kim, J.O.; Barve, A.V.; Silva, S.; Krishna, S.; Brueck, S.R.J.; Nelson, R.; Urbas, A.; et al. Analysis of subwavelength metal hole array structure for the enhancement of back-illuminated quantum dot infrared photodetectors. Opt. Express 2013, 21, 4709-4716. [CrossRef]

41. Fowler, C.; Kim, J.O.; Lee, S.J.; Urbas, A.; Ku, Z.; Zhou, J. Strong Responsivity Enhancement of Quantum Dot-in-a-Well Infrared Photodetectors Using Plasmonic Structures. Adv. Theory Simul. 2019, 2, 1800143. [CrossRef]

42. Gu, G.; Vaillancourt, J.; Vasinajindakaw, P.; Lu, X. Backside-configured surface plasmonic structure with over 40 times photocurrent enhancement. Semicond. Sci. Technol. 2013, 28, 105005.

43. Liu, R.; Vasinajindakaw, P.; Gu, G.; Vaillancourt, J.; Lu, X. Optimizing light absorption in quantum dot infrared photodetectors by tuning surface confinement of surface plasmonic waves. J. Phys. D Appl. Phys. 2012, 46, 015102. [CrossRef] 
44. Shenoi, R.V.; Rosenberg, J.; Vandervelde, T.E.; Painter, O.J.; Krishna, S. Multispectral quantum dots-in-a-well infrared detectors using plasmon assisted cavities. IEEE J. Quantum Electron. 2010, 46, 1051-1057. [CrossRef]

45. Rosenberg, J.; Shenoi, R.V.; Vandervelde, T.E.; Krishna, S.; Painter, O. A multispectral and polarization-selective surface-plasmon resonant midinfrared detector. Appl. Phys. Lett. 2009, 95, 161101. [CrossRef]

46. Ogawa, S.; Komoda, J.; Masuda, K.; Kimata, M. Wavelength selective wideband uncooled infrared sensor using a two-dimensional plasmonic absorber. Opt. Eng. 2013, 52, 127104. [CrossRef]

47. Yamamoto, K.; Goericke, F.; Guedes, A.; Jaramillo, G.; Hada, T.; Pisano, A.P.; Horsley, D. Pyroelectric aluminum nitride micro electromechanical systems infrared sensor with wavelength-selective infrared absorber. Appl. Phys. Lett. 2014, 104, 111111. [CrossRef]

48. Dao, T.D.; Ishii, S.; Yokoyama, T.; Sawada, T.; Sugavaneshwar, R.P.; Chen, K.; Wada, Y.; Nabatame, T.; Nagao, T. Hole array perfect absorbers for spectrally selective midwavelength infrared pyroelectric detectors. ACS Photonics 2016, 3, 1271-1278. [CrossRef]

49. Ahmed, A.S.; Kim, H.J.; Kim, J.; Hwang, K.S.; Kim, S. Enhancing the Responsivity of Uncooled Infrared Detectors Using Plasmonics for High-Performance Infrared Spectroscopy. Sensors 2017, 17, 908. [CrossRef]

50. Safaei, A.; Modak, S.; Lee, J.; Chandra, S.; Franklin, D.; Vázquez-Guardado, A.; Chanda, D. Multi-spectral frequency selective mid-infrared microbolometers. Opt. Express 2018, 26, 32931-32940. [CrossRef]

51. Yu, P.; Wu, J.; Ashalley, E.; Govorov, A.; Wang, Z. Dual-band absorber for multispectral plasmon-enhanced infrared photodetection. J. Phys. D Appl. Phys. 2016, 49, 365101. [CrossRef]

52. Chen, S.; Chen, Z.; Liu, J.; Cheng, J.; Zhou, Y.; Xiao, L.; Chen, K. Ultra-narrow band mid-infrared perfect absorber based on hybrid dielectric metasurface. Nanomaterials 2019, 9, 1350. [CrossRef] [PubMed]

53. Li, Q.; Yu, B.Q.; Li, Z.F.; Wang, X.F.; Zhang, Z.C.; Pan, L.F. Surface plasmon-enhanced dual-band infrared absorber for-based microbolometer application. Chin. Phys. B 2017, 26, 085202. [CrossRef]

54. Utermöhlen, F.; Etter, D.B.; Borowsky, D.; Herrmann, I.; Schelling, C.; Hutter, F.X.; Sun, S.H.; Burghartz, J.N. Low-cost microbolometer with nano-scaled plasmonic absorbers for far infrared thermal imaging applications. In 2014 IEEE 27th International Conference on Micro Electro Mechanical Systems (MEMS); IEEE: Piscataway, NJ, USA, 2014; pp. 572-575.

55. Banks, J.M.; Flammer, P.D.; Furtak, T.E.; Hollingsworth, R.E.; Collins, R.T. Plasmonic Band-Pass Microfilters for LWIR Absorption Spectroscopy. Int. J. Opt. 2012, 2012. [CrossRef]

56. Chen, H.H.; Su, Y.C.; Huang, W.L.; Kuo, C.Y.; Tian, W.C.; Chen, M.J.; Lee, S.C. A plasmonic infrared photodetector with narrow bandwidth absorption. Appl. Phys. Lett. 2014, 105, 023109. [CrossRef]

57. Park, H.S.; Nam, S.H.; Hong, H.G.; Roh, S.; Yun, S.; Kim, J.; Kwon, D.; Chung, U.I. Newly developed broadband plasmonic absorber for uncooled infrared detectors. Proc. SPIE Int. Soc. Opt. Eng. 2014, 8977, 89770I.

58. Ho, Y.L.; Lerondel, G.; Delaunay, J.J. Plasmonic hybrid cavity-channel structure for tunable narrow-band optical absorption. IEEE Photon. Technol. 2014, 26, 1979-1982. [CrossRef]

59. Lu, X.; Vaillancourt, J.; Gu, G. A plasmonic perfect absorber enhanced longwave infrared quantum dot infrared photodetector with high quantum efficiency. J. Phys. D Appl. Phys. 2017, 50, 135101. [CrossRef]

60. Lee, S.C.; Krishna, S.; Brueck, S.R.J. Quantum dot infrared photodetector enhanced by surface plasma wave excitation. Opt. Express 2009, 17, 23160-23168. [CrossRef]

61. Huang, Y.; Lien, C. Strong Stark effect of the intersubband transitions in the three coupled quantum wells: Application to voltage-tunable midinfrared photodetectors. J. Appl. Phys. 1995, 78, 2700-2706. [CrossRef]

62. Fry, P.W.; Itskevich, I.E.; Mowbray, D.J.; Skolnick, M.S.; Finley, J.J.; Barker, J.A.; O’Reilly, E.P.; Wilson, L.R.; Larkin, A.; Maksym, P.A.; et al. Inverted electron-hole alignment in InAs-GaAs self-assembled quantum dots. Phys. Rev. Lett. 2000, 84, 733. [CrossRef] [PubMed]

63. CST Microwave Studio: A Numerical Simulation Software for Electromagnetic Computing, Computer Simulation Technology GmbH, Darmstadt, Germany. Available online: https://www.3ds.com/ (accessed on 13 September 2020).

64. Ito, T.; Okazaki, S. Pushing the limits of lithography. Nature 2000, 406, 1027-1031. [CrossRef] [PubMed]

65. Ordal, M.A.; Bell, R.J.; Alexander, R.W.; Long, L.L.; Querry, M.R. Optical properties of fourteen metals in the infrared and far infrared: $\mathrm{Al}, \mathrm{Co}, \mathrm{Cu}, \mathrm{Au}, \mathrm{Fe}, \mathrm{Pb}, \mathrm{Mo}, \mathrm{Ni}, \mathrm{Pd}, \mathrm{Pt}, \mathrm{Ag}, \mathrm{Ti}, \mathrm{V}$, and W. Appl. Opt. 1985, 24, 4493-4499. [CrossRef] [PubMed] 
66. Li, J.Y.; Hua, Y.-L.; Fu, J.X.; Li, Z.Y. Influence of hole geometry and lattice constant on extraordinary optical transmission through subwavelength hole arrays in metal films. J. Appl. Phys. 2010, 107, 073101. [CrossRef]

67. Yang, S.H.; Bandaru, P.R. Effect of surface texture and geometry on spoof surface plasmon dispersion. Opt. Eng. 2008, 47, 029001. [CrossRef]

68. Maeda, E.; Matsuki, T.; Yamada, I.; Delaunay, J.-J. Hole shape effect induced optical response to permittivity change in palladium sub-wavelength hole arrays upon hydrogen exposure. J. Appl. Phys. 2012, 111, 084502. [CrossRef]

69. Li, J.-Y.; Qiu, K.-S.; Ma, H.-Q. Analysis of phase shift of surface plasmon polaritons at metallic subwavelength hole arrays. Chin. Phys. B 2014, 23, 106804. [CrossRef]

70. Liu, H.; Lalanne, P. Microscopic theory of the extraordinary optical transmission. Nature 2008, 452, 728-731. [CrossRef]

(C) 2020 by the authors. Licensee MDPI, Basel, Switzerland. This article is an open access article distributed under the terms and conditions of the Creative Commons Attribution (CC BY) license (http://creativecommons.org/licenses/by/4.0/). 